\title{
Structure of parasite communities in urban environments: the case of helminths in synanthropic rodents
}

\author{
Diego Hancke and Olga Virginia Suárez
}

Laboratorio de Ecología de Roedores Urbanos, Departamento de Ecología, Genética y Evolución, Facultad de Ciencias Exactas y Naturales, Universidad de Buenos Aires, Buenos Aires, Argentina

\begin{abstract}
Identifying patterns with sufficient predictive power is a constant challenge for ecologists to address ecological problems related to species conservation, pollution or infectious disease control. During the last years, the amounts of parasitological studies in this sense increased, but they are still scarce in urban environments. The main aim of this study was to investigate if the helminth communities of urban rodents are structured within host assembly (compound community) or they are a result of random events occurring at each individual host scale (infracommunity). A total of 203 rodents belonging to four species, Rattus rattus (Linnaeus), Rattus norvegicus (Berkenhout), Mus musculus Linnaeus and the native Oligoryzomys flavescens (Waterhouse) and captured in different landscape units of the City of Buenos Aires (industrial-residential neighbourhoods, shantytowns and parklands) were analysed. The results showed that infracommunities could be grouped according to composition and relative abundances and that they respond to the structure of the host community. Thus, the component communities defined in this study could be identified as subsets of the compound community (rodent assemblage) and infracommunities (each host) as random samples within each one. Quantitative differences among component communities were denoted by comparing the infection levels of helminths described as central species. Therefore, infracommunities of $R$. norvegicus and $O$. flavescens were the most predictable because of the high abundance of the nematodes Heterakis spumosa Schneider, 1866 and Nippostrongylus brasiliensis (Travassos, 1914), and Stilestrongylus flavescens (Sutton et Durette-Desset, 1991), respectively. Several mechanisms contribute to complexity of the structure of parasite communities, where specific parasites, definitive and intermediate hosts, and environmental and anthropogenic factors all play a role in the dynamics of the compound community.
\end{abstract}

Keywords: Parasites, urbanization, infracommunity, component community, compound community, ecology, zoonosis.

The identification of mechanisms shaping parasite community structure has important implications for host health, transmission of infectious diseases and the understanding of biological assemblages in general (Dallas and Presley 2014). During the last few decades, studies searching for recurrent and predictable patterns to identify factors that determine parasite community structures increased (Mouillot et al. 2005, Poulin 2007, Luque and Poulin 2008). Patterns in species diversity may be affected by a variety of ecological and evolutionary processes, as well as historical and geographical contingencies (Poulin 2004). Thus, spatial variations in parasite community composition are driven by both host-associated and environmental-associated factors (Spickett et al. 2017). Historically, most of these studies have been conducted on parasite assemblages in aquatic hosts (see Timi and Lanfranchi 2009, Alarcos and Timi 2012, Carballo et al. 2012) while parasite of terrestrial hosts have received more attention in the last years (Froeschke et al. 2010; Palmeirim et al. 2014; Spickett et al. 2017).

A host represents a suitable environment for the establishment and survival of parasites. Many authors argue that host characteristics such as body size, metabolic rate, trophic status and reproductive characteristics influence the colonisation and propagation of parasite species (Kuris et al. 1980, Combes 2001, Poulin et al. 2011). In general, parasitic communities tend to be similar in hosts that are geographically, phylogenetically, ecologically and developmentally close (Locke et al. 2013). Similarity of parasite community composition is often associated with host characteristics since these affect the transmission and establishment of parasites (Krasnov et al. 2010, Poulin 2010, Rigaud et al. 2010, Locke et al. 2014). The evolutionary distance between hosts has also been mentioned as a predictor of similarity in parasite communities (Locke et al. 2013).

Rodents are hosts for a large number of helminth parasites and are mentioned as main reservoirs for pathogens in human modified habitats, including zoonotic helminth species (Himsworth et al. 2013, Morand et al. 2015). The patterns of infection and spatial variations in helminth community composition have been studied in different rodent assemblages around the world (e.g. Chaisi-

Address for correspondence: Diego Hancke, Laboratorio de Ecología de Roedores, Departamento de Ecología, Genética y Evolución, Facultad de Ciencias Exactas y Naturales, Universidad de Buenos Aires, Avenida Intendente Cantilo s/n, Ciudad Universitaria, Pabellón II, $4^{\circ}$ Piso Laboratorio 104 (C1428EHA), Buenos Aires, Argentina. Tel.: +54 1145763300 int 219; Fax: +54 11 4576 3354; E-mail: diegohancke@ege.fcen.uba.ar 


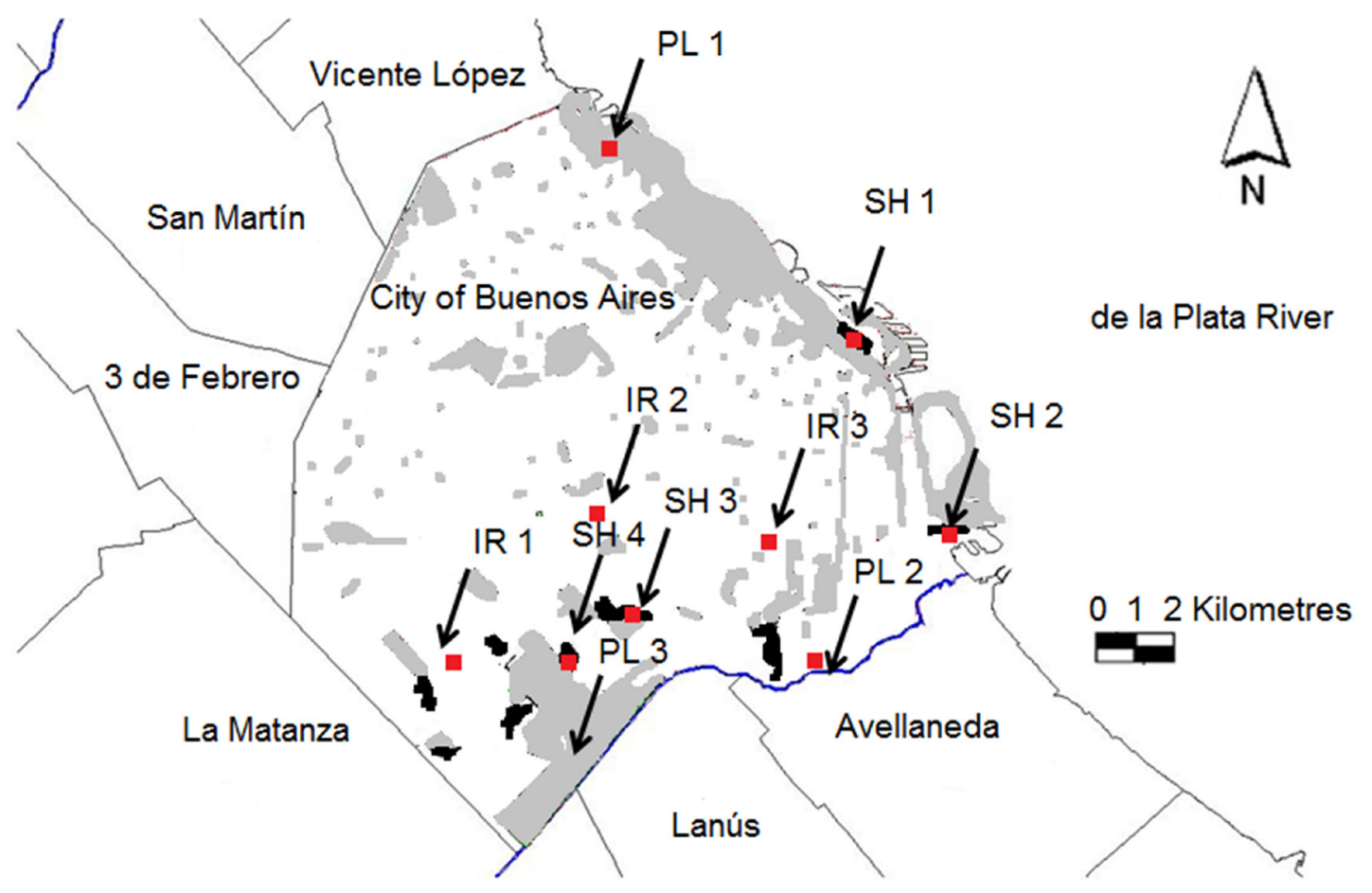

Fig. 1. Map of the city of Buenos Aires showing the ten sites where rodents were sampled. Black arrows indicate the location of the sampled sites. PL 1-3-parklands; SH 1-4-shantytowns; IR 1-3-industrial-residential neighbourhoods. Grey polygons indicate the location of parklands and open green spaces, black polygons correspond to shantytowns and the white foreground corresponds to the matrix of blocks with buildings and pavement reproduced from Hancke and Suárez (2017).

ri et 1. 2016, Spickett et al. 2017). However, within urban landscapes, studies that integrate ecological characteristics of host assembly with parasite compound structure are still scarce. It is generally agreed that cities are characterised by a structural variation and the different intensities of land use creates a great array of different habitats and microhabitats (Werner and Zahner, 2010).

In the City of Buenos Aires, rodent diversity varies according to habitat characteristics. According to Cavia et al. (2009), in highly urbanised environments, such as residential or industrial areas, the dominant species is Rattus rattus (Linnaeus). In environments with a lower degree of urbanisation, as in the case of shantytowns, the dominant species are Rattus norvegicus (Berkenhout) and Mus musculus Linnaeus (see Cavia et al. 2009). In parks and green spaces, $R$. norvegicus and M. musculus are also the most abundant species but accompanied by Oligoryzomys flavescens (Waterhouse), a native sigmodontine rodent (Cavia et al. 2009). So six groups of hosts could be distinguished as a result of the combination between rodent species and habitat (R. norvegicus and M. musculus in shantytowns and parklands, $R$. rattus in residential neighbourhoods and $O$. flavescens in parklands). Given this context, and considering the importance of these animals in public health of densely populated areas like cities, we queried the potential relationship between variations in urban rodent assemblages and the corresponding helminth communities' structure.

Several studies have explored the interconnection of hierarchical levels in parasitic organisations (infracommunities component communities-compound communities; see Bush et al. 1997 for more details), mainly in aquat- ic environments (e.g. Luque and Poulin 2008, Timi and Lanfranchi 2009). Holmes (1990) developed a theoretical framework that relates the structure of the different hierarchical levels and predicts whether infracommunities or components communities could be defined as subsets or random samples of a compound community. If the component community is determined by the phylogenetical, ecological or physiological specificity of parasites, then it will be essentially a subset of the compound community and the infracommunities random samples of each subset. Should infracommunities depend upon physiological or ecological traits acting at the level of individual host, then they will be random samples of the compound community directly (being component communities artificial entities). According to Timi and Lanfranchi (2009), both situations are the opposite ends of a continuous pattern rather than mutually exclusive alternatives.

The main aim of this study was to determine if infracommunity structures of urban rodents respond to the component communities to which they belong or if they are the result of random events occurring at each individual host level. We analysed patterns of similarity in helminth infracommunities composition between and within rodent species captured in different landscape units of the City of Buenos Aires (Argentina) to understand the mechanisms of spatial variation of parasite communities within an urban context.

Therefore, two hypotheses were made. First, transmission and establishment of parasites are affected by biological, ecological or phylogenetical features of the hosts, so that greater similarities of infracommunities were expected 
within rodents of the six groups of hosts mentioned above than between them. Second, many parasitic species exhibit host preferences as a function of shared evolutionary history, so the greatest dissimilarity in infracommunities composition was expected between the only native species $O$. flavescens and the rest of the groups.

\section{MATERIALS AND METHODS}

\section{Study area}

Buenos Aires ( $34^{\circ} 37^{\prime \prime S}$; $\left.58^{\circ} 24^{\prime \prime} \mathrm{W}\right)$, the main city of Argentina in terms of population, occupies an area of around $200 \mathrm{~km}^{2}$ and is one of the largest metropolises of the world (United Nations 2012). The climate is temperate with a mean annual temperature of $17.5^{\circ} \mathrm{C}$, seasonal amplitude of $13.3^{\circ} \mathrm{C}$ and mean annual precipitation of $1,014 \mathrm{~mm}$. Rodent samples were examined from three landscape units including three parklands, four shantytowns and three industrial-residential sites. The sites were not contiguous and were spaced by at least $1 \mathrm{~km}$ and separated by barriers such as railroad tracks, avenues, highways, etc. (Fig. 1).

Parklands refer to public areas of recreation, where areas of spontaneous vegetation and woodlots with planted species are included in a matrix of grass or ornamental lawn (Cavia et al. 2009). The parklands studied were located on the banks of the Río de la Plata River and the Riachuelo River, both of which allow the entry of native flora and fauna to an urban ecosystem (Cavia et al. 2009)

Shantytowns refer to areas inhabited by a very low-income population that lives in precarious dwellings with an inadequate supply of basic urban services, such as garbage removal, sanitation networks, electricity, telephones and plumbing (Fernández et al. 2007, Hancke and Suárez 2014).

Industrial residential areas refer to neighbourhoods where buildings and pavement are the dominant elements in the landscape unit. In these neighbourhoods, the dominant types of construction are houses of no more than two stories, but in some sections there are also industries and apartment block buildings. Different kinds of stores may be found along avenues (Cavia et al. 2009).

\section{Collection and examination of rodents}

Rodents were collected during surveys carried out as part of a rodent control programme in the city of Buenos Aires. The disadvantage of working with urban rodents is that they are very difficult to capture and quantify during field research (Himsworth et al. 2014). In order to achieve an acceptable number of samples, it was necessary to consider an extended period of time, from 2004 to 2011. In spite of this broad span of time, it has been previously shown that the year of host capture had no effect on helminth richness and diversity in our study case, as well as host body size and gender (Hancke and Suárez 2017).

Rodents from the three landscape sites were collected during the spring and summer (between October and March), when mean temperature was $17^{\circ} \mathrm{C}$ or more and mean precipitation above $100 \mathrm{~mm}$, and during the autumn and winter (between April and September), when mean temperature was below $17^{\circ} \mathrm{C}$ and mean precipitation $100 \mathrm{~mm}$ or less. The animals were captured using live cage traps, wire-mesh traps of $15 \times 16 \times 31 \mathrm{~cm}$ with a door that is locked, openable with a pin connected to a trigger device holding the bait and Sherman trap, an aluminium box-trap $(8 \times 9 \times 23 \mathrm{~cm})$ with a door open at one end leading to a weight-sensitive treadle. Traps were placed inside houses and in their yards, in stores or factories, or on lines in sites dominated by vegetation. Sherman traps were baited with a mixture of peanut butter and cow fat, and cage traps with carrot and raw meat; they were monitored every morning for four consecutive days. Captured animals were killed with anesthesia, fixed in formaldehyde and a week later preserved in $70 \%$ ethanol and deposited in the collection of the Laboratory of Urban Rodents Ecology (University of Buenos Aires).

Only sexually mature rodents were kept for this study since juveniles are less likely to harbour parasites due to their reduced times of exposure to infection (Chaisiri et al. 2015). The entire alimentary tract was removed and carefully scrutinised for helminth parasites. When found, these were removed carefully, identified, counted and preserved in $70 \%$ ethanol.

\section{Data analysis}

Within the rodent assembly of Buenos Aires six different groups of hosts or component communities were defined: Rattus rattus from residential neighbourhoods, Rattus norvegicus from shantytown, Mus musculus from shantytown, R. norvegicus from parklands, M. musculus from parklands and Oligoryzomys flavescens from parklands. Parasite communities were analysed at the scale of individual rodent (i.e. the 203 parasite infracommunities).

First, to analyse if sampling sites eventually exhibited qualitatively different helminth fauna for any of the rodent species involved, a hierarchical cluster analysis was performed (using the Jaccard index as measure of distance and average linkage method) to study the similarity between sampling sites in terms of helminth infracommunity composition. The combination of rodent species and sampling site was used as classification criteria. Then, the similarity of helminth infracommunities in the compound community was measured qualitatively and quantitatively using Jaccard and Bray Curtis indexes, respectively, and the separation of infracommunities was graphically explored by non-metric multidimensional scaling methods (NMDS) (Clarke 1993). The data matrix was constructed taking the absolute abundance of all helminth species in each host. As it is usually seen in macroparasite abundance data, excessive zero counts were evident in the sample. To preserve the low incidence of some parasite species a zero-adjusted Bray-Curtis coefficient was applied, so empty host could be considered and the differences at low abundances were smoothed (Clarke et al. 2006).

Analyses of similarity (ANOSIM) were conducted to test statistical differences between groups of infracomunities. ANOSIM is a non-parametric test of significant difference between two or more groups based on any distance measure (Clarke 1993). The test is based on comparing distances between groups with distances within groups. Large positive R statistic value (up to 1) indicates dissimilarity between groups, whereas weak or negative value (up to -1) indicates strong similarity between groups. The significance was computed by permutation of group memberships, with 10,000 replicates and significantly differences were considered with $\mathrm{p}$ values lower than 0.05. ANOSIM analyses were applied to test the differences between each of the pairs of the six groups of hosts previously defined ( 15 comparisons in total). 


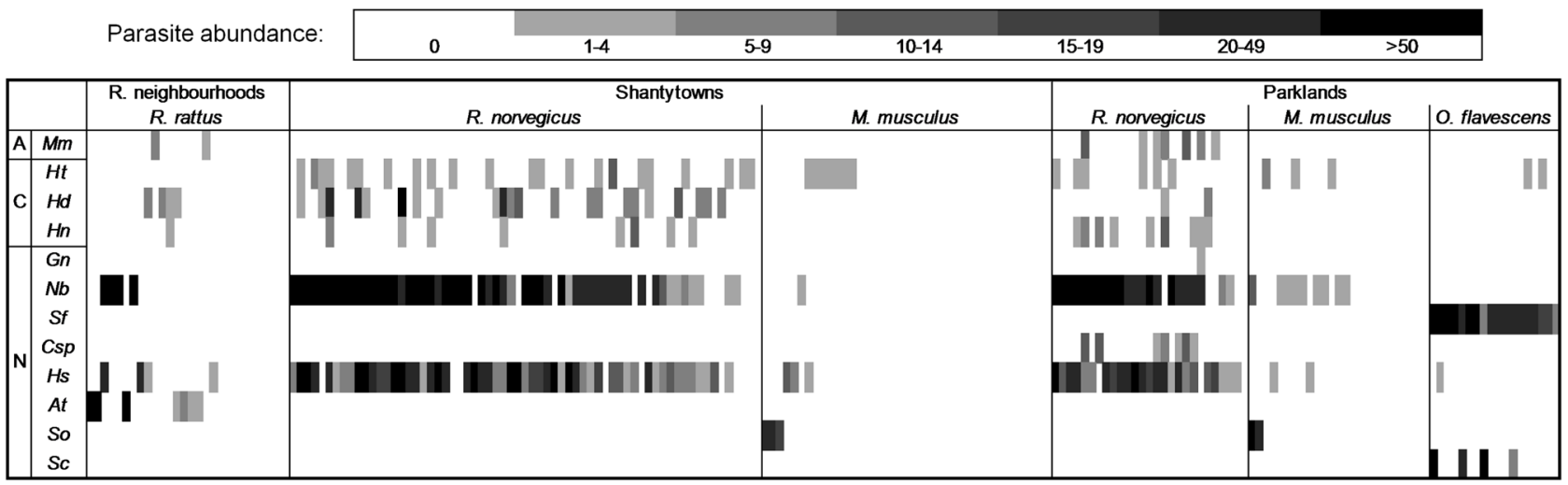

Fig. 2. Heat map showing infection levels of 12 helminth species in 203 rodents of 4 rodent species captured in three landscape units of the City of Buenos Aires. Each column shows the abundance of helminths in an individual rodent and each row shows the distribution of a parasite species among the hosts. Within each host species of each landscape unit, rodents are ordered from left to right from higher to lower infection levels. A - acantocephalans; Mm - Moniliformis moniliformis (Bremser, 1811); C - cestodes; Ht - Hydatigera taeniaeformis (Batsch, 1786); Hd - Hymenolepis diminuta (Rudolphi, 1819); Hn - Hymenolepis nana (Siebold, 1852); N - nematodes; $\mathrm{Gn}$ - Gongylonema neoplasticum (Fibiger et Ditlevsen, 1914); Nb - Nippostrongylus brasiliensis (Travassos, 1914); Sf - Stilestrongylus flavescens (Sutton et Durette-Desset, 1991); Csp - Capillaria sp.; Hs - Heterakis spumosa Schneider, 1866; At - Aspiculuris tetraptera (Nitzsch, 1821); So - Syphacia obvelata (Rudolphi, 1802); Sc - Syphacia carlitosi del Robles et Navone, 2007. The helminth abundance within each host specimen is indicated through a grayscale.

Table 1. N - number of rodents examined at each sampling site of three landscape units of the City of Buenos Aires; \% - the percentage of infected animals with any hel minth species; $\mathrm{n}$ - the number of helminth species observed in each site for each rodent species; IR 1-3 - industrial-residential neighbourhoods; SH 1-4-shantytowns; PL 1-3-parklands. The sampling sites are shown in Fig. 1.

Rattus rattus (Linnaeus) Rattus norvegicus (Berkenhout) Mus musculus Linnaeus Oligoryzomys flavescens (Waterhouse)

\begin{tabular}{|c|c|c|c|c|c|c|c|c|c|c|c|c|c|}
\hline \multirow{5}{*}{ 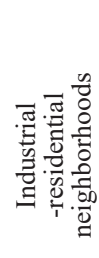 } & & $\mathrm{N}$ & $\%$ & $\mathrm{n}$ & $\mathrm{N}$ & $\%$ & $\mathrm{n}$ & $\mathrm{N}$ & $\%$ & $\mathrm{n}$ & $\mathrm{N}$ & $\%$ & $\mathrm{n}$ \\
\hline & IR1 & 17 & 47 & 4 & & & & & & & & & \\
\hline & IR2 & 7 & 100 & 2 & & & & & & & & & \\
\hline & IR3 & 4 & 75 & 3 & & & & & & & & & \\
\hline & Total & 28 & 64 & 6 & & & & & & & & & \\
\hline \multirow{5}{*}{ 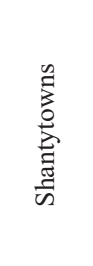 } & SH1 & & & & 40 & 98 & 5 & 10 & 30 & 2 & & & \\
\hline & $\mathrm{SH} 2$ & & & & 10 & 100 & 5 & 10 & 30 & 1 & & & \\
\hline & SH3 & & & & 8 & 100 & 5 & 10 & 40 & 3 & & & \\
\hline & SH4 & & & & 7 & 100 & 3 & 10 & 30 & 2 & & & \\
\hline & Total & & & & 65 & 99 & 5 & 40 & 33 & 4 & & & \\
\hline \multirow{4}{*}{ 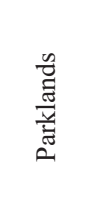 } & PL1 & & & & 10 & 100 & 8 & 10 & 60 & 3 & 6 & 100 & 3 \\
\hline & PL2 & & & & 7 & 86 & 5 & 6 & 67 & 3 & 10 & 100 & 3 \\
\hline & PL3 & & & & 10 & 100 & 7 & 9 & 44 & 3 & 2 & 100 & 1 \\
\hline & Total & & & & 27 & 96 & 8 & 25 & 56 & 4 & 18 & 100 & 4 \\
\hline
\end{tabular}

Finally, the SIMPER method was used to determine which helminth species (variables) are contributing most to the dissimilarity between groups of rodents (sampling units). SIMPER (similarity percentages - Clarke and Warwick 1994) computes the percentage of dissimilarity and the percentage contribution of each parasite species to the dissimilarities between each pair of groups of hosts. All analyses were performed with software R using vegan package (R Development Core Team 2014).

\section{RESULTS}

A total of 28 Rattus rattus, 92 Rattus norvegicus, 65 Mus musculus and 18 Oligoryzomys flavescens were captured and analysed for parasitological screening (Table 1). Of the 203 rodents, 153 were parasitised and 12 species of helminths belonging to three different groups were identified. More detailed information on infection parametres of these parasites is provided in Hancke and Suárez (2017). The levels of infection of the helminth species found in each host at each landscape unit, are summarised in Fig. 2.

Figure 3 shows that there are no sampling sites with marked qualitatively different helminth characteristics. Three groups of the 19 possible combinations of sampling sites and rodent species could be distinguished with $80 \%$ of dissimilarity. The first group corresponded to the sites 


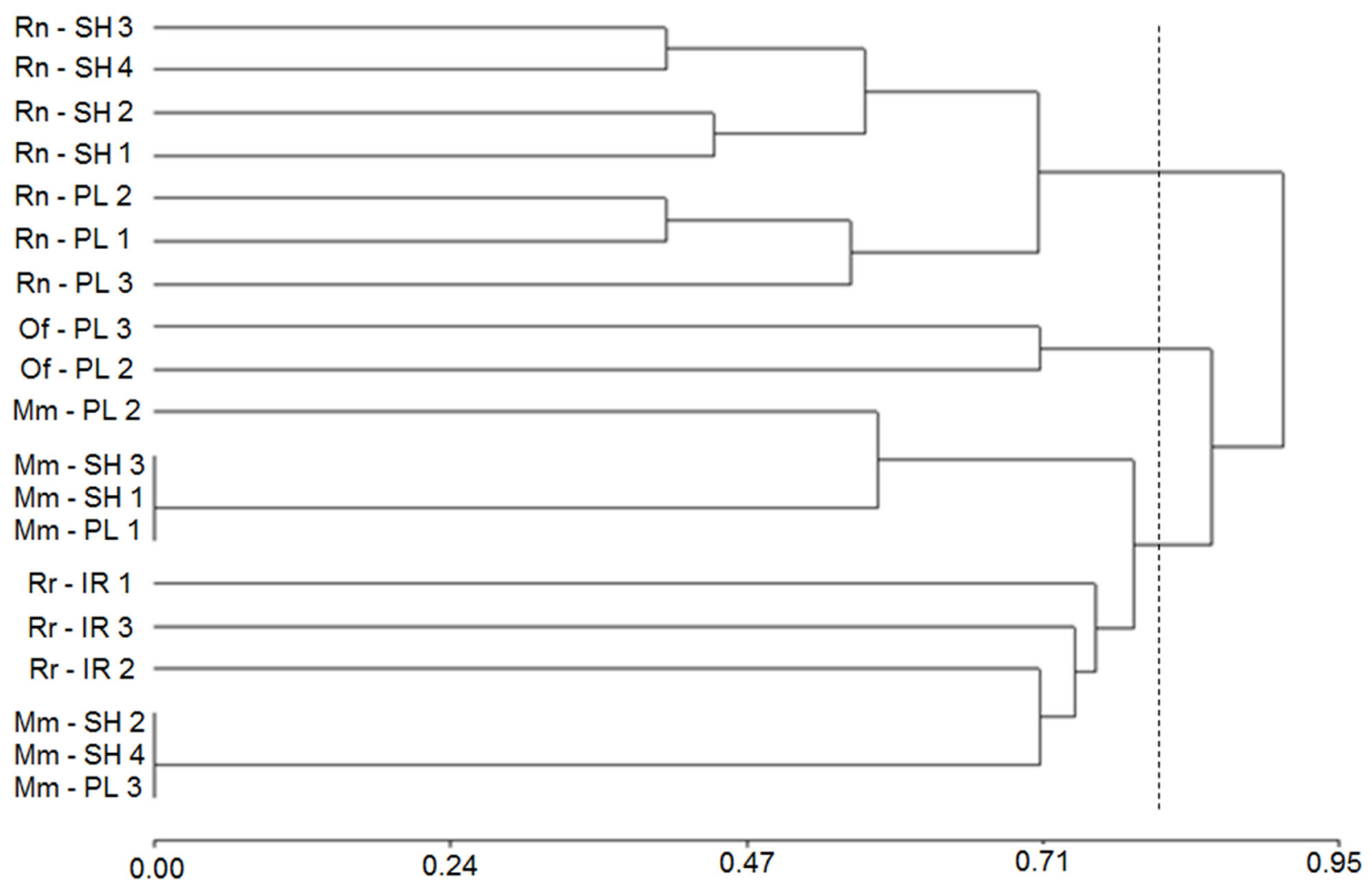

Fig. 3. Dendogram representing the hierarchical cluster analysis of the helminth communities for each rodent species in sampling site. The initials represents the different combinations of rodent and sampling site: $\mathrm{Rn}$-Rattus norvegicus (Berkenhout); $\mathrm{Rr}-$ Rattus rattus (Linnaeus); Mm - Mus musculus Linnaeus; Of - Oligoryzomys flavescens (Waterhouse); PL 1-3 - parklands, SH 1-4 - shantytowns and IR 1-3 - industrial-residential neighbourhoods. The sampling sites are shown in Fig. 1. The horizontal axis represents dissimilarity (1 - Jaccard index).

for $R$. norvegicus (shantytowns and parklands), the second group corresponded to $O$. flavescens sites and the third group consisted of the capture sites for M. musculus and $R$. rattus. Within the group of the brown rats, it was possible to distinguish the sampling sites of shantytowns and parklads, whereas for M. musculus no distinction could be observed.

The helminth infracommunities of the rodent assemblage of the City of Buenos Aires could be structured better from a quantitative than from a qualitative aspect. It was not possible to distinguish a clear clustering in the NMDS using Jaccard index (Fig. 4). In contrast, two clearly differentiated subsets could be observed while using Bray-Curtis similarity coefficient, those infracommunities belonging to $O$. flavescens and those to $R$. norvegicus (parklands and shantytowns, both). The points representing M. musculus and $R$. rattus showed a more dispersed disposal. It can also be noted that there is no sampling site showing a particular or distinctive trend within this analysis.

These patterns in NMDS were statistically tested with the analysis of similarities (ANOSIM, 10,000 permutations). First, infracommunities were not homogeneous within the rodents assemblage and significant differences were detected within groups of host in general $(\mathrm{R}=0.5$; $\mathrm{p}<0.001)$. When comparing each of the pairs of the six groups of host (15 comparisons in total), significant dissimilarities were detected in all of them except among the infracomunities of $R$. norvegicus from shantytown and $R$. norvegicus from parklands $(\mathrm{R}=-0.05 ; \mathrm{p}=0.9)$.

A resume of the SIMPER analysis results for the 15 comparisons highlights the helminth species that most contributed to explain the dissimilarity of the infracommunities calculated with Bray Curtis coefficients (Table 2). The species that mostly contributed to differentiate the parasitic composition of $R$. norvegicus and $O$. flavescens with the remaining host assembly were the trichostrongylid nematode Nippostrongylus brasiliensis (Travassos, 1914) and Stilestrongylus flavescens (Sutton et Durette-Desset, 1991), respectively. Besides, Heterakis spumosa Schneider, 1866 helped to explain $25-30 \%$ of the differences between brown rats and the rest of the hosts.

Overall, the infracommunities of $O$. flavescens differentiated markedly from the rest of the compound community and a significant similarity was found between the composition of the infracommunities of $R$. norvegicus from shantytowns and parklands, which was not the case for M. musculus living in sympatry.

\section{DISCUSSION}

In this study we suggest that infracommunities of rodents in the City of Buenos Aires could be grouped according to their composition and relative abundances and that they respond to the structure of host community. Therefore, and following Holmes (1990), the component 

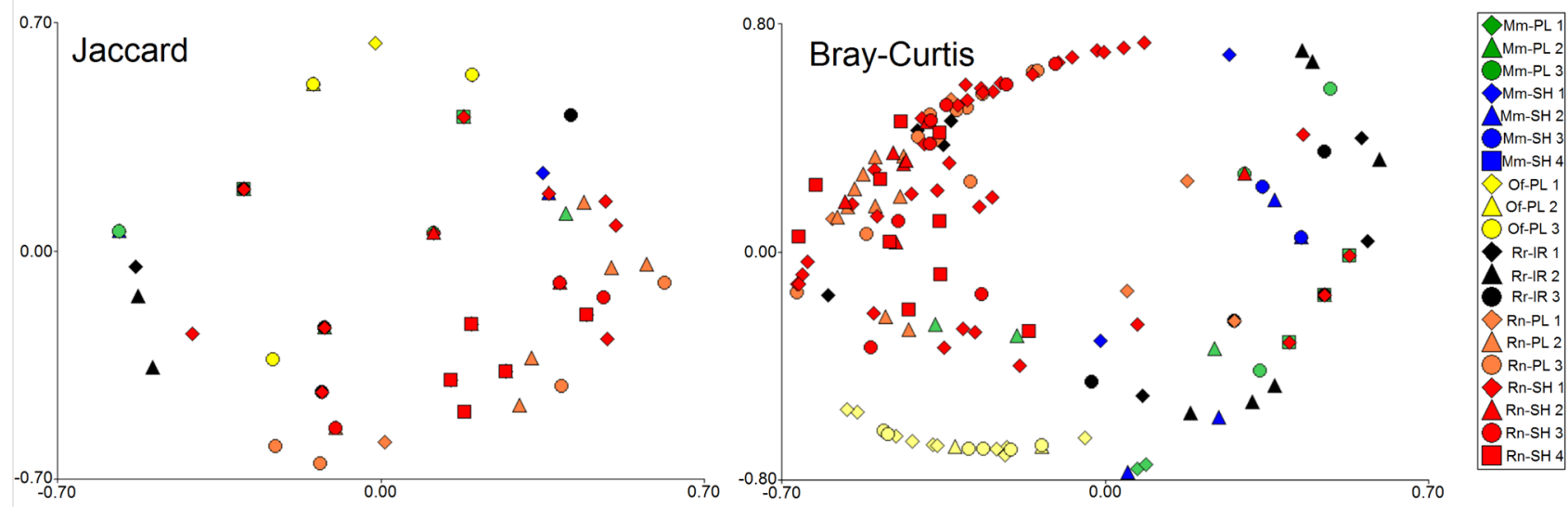

Fig. 4. Non-metric multi-dimensional scaling of Jaccard and Bray-Curtis similarity matrices of helminth abundance data in 203 individual rodents in six groups of hosts resulting from the combination of the species of rodent and the landscape units where the animals were trapped. The form of the symbols represents the sampling sites within each landscape unit. Stress values indicate that multivariate distances are well represented in two dimensions (Clarke, 1993). Mm - Mus musculus Linnaeus; Of - Oligoryzomys flavescens (Waterhouse); Rr - Rattus rattus (Linnaeus); Rn - Rattus norvegicus (Berkenhout); PL 1-3 - parklands; SH 1-4 - shantytowns and IR 1-3 - industrial-residential neighbourhoods.

Table 2. Helminth species with more than a $20 \%$ contribution to explain up to $70 \%$ of the pairwise dissimilarity in infracommunity composition among the 6 groups of rodents of the City of Buenos Aires. Mean $\mathrm{C}$ - percentage contribution to dissimilarity; Max $\mathrm{C}$ - maximum contribution; $\mathrm{N}$ - number of pairs in which a given species contributed to dissimilarity; $\mathrm{Ab}$ - mean abundance of a given species.

\begin{tabular}{|c|c|c|c|c|c|c|c|c|c|}
\hline \multicolumn{5}{|c|}{ Rattus norvegicus (Berkenhout) - Shantytowns } & \multicolumn{5}{|c|}{ R. norvegicus - Parklands } \\
\hline$\underline{\text { Parasite }}$ & Mean C & Max C & $\mathrm{N}$ & $\mathrm{Ab}$ & Parasite & Mean C & Max C & $\mathrm{N}$ & $\mathrm{Ab}$ \\
\hline $\begin{array}{l}\text { Nippostrongylus brasiliensis } \\
\text { (Travassos, 1914) }\end{array}$ & 54 & 64 & 5 & 106 & N. brasiliensis & 40 & 57 & 4 & 62 \\
\hline $\begin{array}{l}\text { Heterakis spumosa } \\
\text { Schneider, } 1866\end{array}$ & 22 & 29 & 4 & 24 & H. spumosa & 18 & 31 & 3 & 22 \\
\hline
\end{tabular}

\begin{tabular}{|c|c|c|c|c|c|c|c|c|c|}
\hline \multicolumn{5}{|c|}{ Mus musculus Linnaeus - Shantytowns } & \multicolumn{5}{|c|}{ M. musculus - Parklands } \\
\hline Parasite & Mean C & Max C & $\mathrm{N}$ & $\mathrm{Ab}$ & Parasite & Mean C & Max C & $\mathrm{N}$ & $\mathrm{Ab}$ \\
\hline & & & & & N. brasiliensis & 7 & 33 & 1 & 1 \\
\hline- & - & - & - & - & $\begin{array}{l}\text { Syphacia obvelata } \\
\text { (Rudolphi, 1802) }\end{array}$ & 6 & 31 & 1 & 7 \\
\hline
\end{tabular}

\begin{tabular}{lcccccccc}
\multicolumn{3}{c}{ Rattus rattus (Linnaeus) } & \multicolumn{4}{c}{ Oligoryzomys flavescens (Waterhouse) } \\
\hline Parasite & Mean C & Max C & N & Ab & Parasite & Mean C & Max C & N \\
N. brasiliensis & 11 & 33 & 2 & 11 & S. flavescens & 61 & 83 & 5 \\
Aspicularis tetraptera & 11 & 29 & 2 & 13 & & &
\end{tabular}

communities defined in this study could be identified as subsets of the compound community (rodent assemblage) and the infracommunities (each host) as random samples within each one. Although this type of hypothesis has been recently studied in other helminth-rodent systems (Bordes et al. 2017, Spickett et al. 2017), this is the first empirical study conducted within an urban context. As urban environments are constantly expanding and the biological processes occurring in cities, such as habitat productivity, competition between species and trophic dynamics, are altered with respect to natural environments (Shochat et al. 2006), we consider that the information obtained in this work is relevant.

The infracommunities could be grouped into five different subsets, but even each subset presented its own helminth composition, the main differences were rather quantitative than qualitative: Rattus norvegicus (from shantytowns and parklands), Rattus rattus, Mus musculus from shantytowns, M. musculus from parklands and $\mathrm{Ol}$ igoryzomys flavescens. According to Holmes (1990), the predictability of infracommunities can be assessed based on the number of core species, while the predictability of component communities is based on the similarity between infracommunities. Quantitative differences between component communities are denoted by comparing the levels of infection of helminth described as central species. These species were generalist species, as in the case of Heterakis spumosa and Nippostrongylus brasiliensis, or specialist species, Stilestrongylus flavescens. Therefore, infracommunities of $O$. flavescens and $R$. norvegicus were the most predictable of the rodent assemblage in the City of Buenos Aires. The Fig. 2 shows that the nematode $H$. spumosa was present in all component communities, whereas N. brasiliensis and Hydatigera taeniaeformis (Batsch, 1786) were present in three of the four host. In addition, other species such as Hymenolepis nana (Siebold, 1852), Hymenolepis 
diminuta (Rudolphi, 1819) and Moniliformis moniliformis (Bremser, 1811) were detected in two host species.

Infracommunities of $O$. flayvescens were characterised by the presence of $S$. flavescens. Two terms must be taken into account when considering a species as a good community descriptor: specificity and fidelity (Dufrene and Legendre 1997). Specificity refers to the proportion of a given species present in a component community with respect to the total abundance of this species within the host assembly. Fidelity describes the proportion of infracommunities within a component community harbouring a particular species of parasite. The high similarity observed between infracommunities of $O$. flavescens can be interpreted in terms of high specificity and fidelity of $S$. flavescens, since it was only found in specimens of $O$. flavescens and all of them were parasitised with this species (Fig. 2). Besides, component communities of $R$. norvegicus from shantytowns and parklands did not differ in the structure of their infracommumnities. In both cases, the same core species were detected ( $N$. brasiliensis and H. spumosa) with similar relative abundances (Fig. 2).

However, at a sampling site level, the cluster analysis revealed a more similarity within each landscape units for $R$. norvegicus than between of them. This could be explained because more helminth species were found in parklands (8) than in shantytowns (5). These species, i.e. M. moniliformis, Capillaria sp. and Gongylonema neoplasticum (Fibiger et. Ditlevsen, 1914), had low abundances, thus they had no influence on the predictability of infracommunities. A common source of spatial variation in ecological communities is the geographic distance between host populations, in part of a decrease in environmental similarity with increasing distance (Spickett et al. 2017).

In our study case, no spatial correlations in host composition or in landscape structure were previously found (Cavia et al. 2009). Nippostrongylus brasiliensis is a geohelminth that requires the presence of soil to complete it life cycle. In previous studies conducted in Buenos Aires, the presence of $R$. norvegicus was associated with vegetated urban cover and the presence of trees, shrubs and water bodies (Cavia et al. 2009). Shantytowns and parklands feature those characteristics, which could favour the development of infective forms of $N$. brasiliensis in the environment. In contrast $H$. spumosa, a direct life cycle nematode, would be positively associated with host population size and the nesting behaviour of brown rats (Arneberg 2002). In both landscape units, $R$. norvegicus is a numerically dominant rodent (Cavia et al. 2009) and can form large colonies up to more than 30 individuals (Timm 1994). These conditions favour the transmission of geohelminths and other parasites with a direct life cycle.

Unlike $R$. norvegicus and $O$. flavescens, the component communities of $R$. rattus and $M$. musculus did not exhibit core species. Their infracommunities showed consequently a higher variability and a lower predictability. Rattus rattus and $M$. musculus had an overall species richness of six and four, respectively, while each infracommunity was rarely infected with more than one helmith species. These infracommunities can consequently be classified as unsatu- rated, because the parasite richness in each host was much smaller regarding the richness observed at host population level.

Mus musculus was infected with the same four helminth species in shantytowns and parklands, three of them shared with $R$. norvegicus (Fig. 2). The similarity in the helminth composition of both hosts can be related to their phylogenetic relationship and similar environmental requirements. However, the component communities of M. musculus from both landscape units exhibited quantitative differences. In shantytowns mouses were predominantly captured inside the housings, explaining the lower abundance of parasites, principally $N$. brasiliensis. The two species that contributed more to differentiate the infracommunities of both populations were $N$. brasiliensis and Syphacia obvelata (Rudolphi, 1802), a geohelminth and a directly transmitted parasite, whose infectivity and survival would be compromised in closed constructed buildings.

Rattus rattus and $R$. norvegicus are morphologically and behaviourally similar, but $R$. rattus has the ability to climb and build nests with artificial materials, having a more aerial behaviour than $R$. norvegicus (see Marsh 1994, Cavia et al. 2009). In the city of Buenos Aires, $R$. rattus is the numerically dominant species in residential neighbourhoods and use microhabitats like trees, roofs and cables, which could respond to a strategy of spatial segregation to reduce competitive interactions with $R$. norvegicus (see King et al. 2011). Thus, black rats exhibit more aerial movements, less populated colonies and a minor contact with soil, vegetation, domestic animals or others possible sources of helminths' infective stages.

The second hypothesis in this study assumes greater similarity between infracommunities of phylogenetically related hosts. Comparing the six component communities, greater dissimilarities were detected between the only native rodent, $O$. flavescens, and the rest of the synanthropic species. They were clearly distinguished in the NMDS graph and featured an exclusively core species. Despite the results, it was not possible to distinguish whether the pattern observed is due to a phylogenetic distance effect or due to ecological variables such as microenvironmental use, foraging behaviour, competition, changes in mortality rates, among others. It has been observed that in fishes, ecological convergence is a predictor of similarities of parasite communities equal or stronger than host genetic distances (Poulin 2010, Locke et al. 2012). In rodents, in a meta-analysis involving 15 host species of New Mexico (USA), Dallas and Presley (2014) found that most species of parasites have a strict host specificity, indicating the importance of co-evolutionary or co-adaptive relationships between hosts and parasites. However no previous studies have been done in this regard in urban invasive vertebrates.

The search by community ecologists to establish patterns and general laws is not unrelated to epistemological controversies (Jaksic and Marone 2007). In accordance with Poulin (2007), a high degree of contingency was observed in the patterns described in this study. The structure of the component communities in rodent assemblies of Buenos Aires are a result of an association between the 
host community attributes and the environmental characteristics. Several mechanisms contribute to the complexity of parasite communities, where the parasites itself, the definitive and intermediate hosts and the environmental and anthropogenic factors all play a role in the dynamics of a compound community (Dallas and Presley 2014). However, the search and identification of general patterns with adequate predictive power within a biological community as performed in this study is useful to address issues related to urban sustainable development, such as zoonotic infectious disease control.

Acknowledgements. The authors wish to thank all the team of the Laboratorio de Ecología de Roedores Urbanos for their assistance during the field sampling. We are also grateful to Graciela Navone (CEPAVE-CONICET-La Plata-Argentina) for her help provided during helminth identification and her valuable comments on earlier versions of the manuscript. Financial support was provided by University of Buenos Aires, Gobierno de la Ciudad de Buenos Aires and CONICET (Argentina).

\section{REFERENCES}

Alarcos A.J., Timi J.T. 2012: Parasite communities in three sympatric flounder species (Pleuronectiformes: Paralichthyidae). Parasitol. Res. 110: 2155-2166.

Arneberg P. 2002: Host population density and body mass as determinants of species richness in parasite communities: comparative analyses of directly transmitted nematodes of mammals. Ecography 25: 88-94.

Bordes F., Caron A., Blasdell K., Garine-Wichatitsky M., MorAND S. 2017: Forecasting potential emergence of zoonotic diseases in South-East Asia: network analysis identifies key rodent hosts. J Appl Ecol. 54: 691-700.

Bush A.O., Lafferty K.D., Lotz J.M., Shostak A.W. 1997: Parasitology meets ecology on its own terms: Margolis et al. revisited. J. Parasitol. 83: 575-583.

Carballo M.C., Cremonte F., Navone G.T., Timi J.T. 2012: Similarity in parasite community structure may be used to trace latitudinal migrations of Odontesthes smitti along Argentinean coasts. J. Fish Biol. 80: 15-28.

Cavia R., Cueto G.R., Suárez O.V. 2009: Changes in rodent communities according to the landscape structure in an urban ecosystem. Landscape Urban Plan. 90: 11-19.

Chaisiri K., Chou M., Siew C.C., Morand S., Ribas A. 2016: Gastrointestinal helminth fauna of rodents from Cambodia: emphasising the community ecology of host-parasite associations. J Helminthol. 91: 726-738.

Chaisiri K., Siribat P., Ribas A., Morand S. 2015: Potentially zoonotic helminthiases of murid rodents from the Indo-Chinese peninsula: impact of habitat and the risk of human infection. Vector Borne Zoonotic Dis. 15: 73-85.

Clarke K.R. 1993: Non-parametric multivariate analyses of changes in community structure. Aust. J. Ecol. 18: 117-143.

Clarke K.R., Somerfield P.J., Chapman M.G., 2006: On resemblance measures for ecological studies, including taxonomic dissimilarities and a zero-adjusted Bray-Curtis coefficient for denuded assemblages. J. Exp. Mar. Biol. Ecol. 330: 55-80.

Clarke K.R., Warwick R.M. 1994: Change in Marine Communities: An Approach to Statistical Analysis and Interpretation. PRIMER-E Ltd, Plymouth, 144 pp.

Combes C. 2001: Parasitism: The Ecology and Evolution of Intimate Interactions. University of Chicago Press, Chicago, $552 \mathrm{pp}$.

Dallas T., Presley S.J. 2014: Relative importance of host environment, transmission potential and host phylogeny to the structure of parasite metacommunities. Oikos 123: 866-874.

Dufrêne M., Legendre P. 1997: Species assemblages and indicator species: the need for a flexible asymmetrical approach. Ecol. Monogr. 67: 345-366.

Fernández M.S., Cavia R., Cueto G.R., Suárez O.V. 2007: Implementation and evaluation of an integrated program for rodent control in a shantytown of Buenos Aires City, Argentina. EcoHealth 4: 271-277.

Froeschke G., Harf R., Sommer S., Matthee S. 2010: Effects of precipitation on parasite burden along a natural climatic gra- dient in southern Africa - implications for possible shifts in infestation patterns due to global changes. Oikos 119: 1029-1039.

HANCKE D., SuÁREZ O.V. 2014: Environmental health education in schools as strategy for rodent control: an experience in a shantytown of Buenos Aires, Argentina. EcoHealth 11: 133-140.

Hancke D., SuÁrez O.V. 2017: Helminth diversity in synanthropic rodents from an urban ecosystem. EcoHealth 14: 603-613.

Himsworth C.G., Jardine C.M., Parsons K.L., Feng A.Y.T., PATRICK D.M. 2014: The characteristics of wild rat (Rattus spp.) populations from an inner-City neighborhood with a focus on factors critical to the understanding of rat-asociated zoonoses. PLoS ONE 9: e91654.

Himsworth C.G., Parsons K.L., Jardine C., Patrick D.M. 2013: Rats, cities, people, and pathogens: a systematic review and narrative synthesis of literature regarding the ecology of rat-associated zoonoses in urban centers. Vector Borne Zoonotic Dis. 13: $349-359$.

Holmes J.C. 1990: Helminth communities in marine fishes. In: G.W. Esch, A.O. Bush, J.M. Aho (Eds.), Parasite Communities: Patterns and Processes. Springer, Dordrecht, pp. 101-130.

Jaksic F.M., Marone L. 2007: Ecología de Comunidades. Ediciones Universidad Católica de Chile, Santiago, $336 \mathrm{pp}$.

King C.M., Foster S., Miller S. 2011: Invasive European rats in Britain and New Zealand: same species, different outcomes. J. Zool. 285: 172-179.

Krasnov B.R., Mouillot D., Shenbrot G.I., Khokhlova I.S., Vinarski M.V., Korallo-Vinarskaya N.P., Poulin R. 2010: Similarity in ectoparasite faunas of Palaearctic rodents as a function of host phylogenetic, geographic or environmental distances: which matters the most? Int. J. Parasitol. 40: 807-817.

Kuris A.M., Blaustein A.R., Alio J.J. 1980: Hosts as islands. Am. Nat. 116: 570-586.

Locke S.A., Levy M.S., Marcogliese D.J., Ackerman S., McLaughlin J.D. 2012: The decay of parasite community similarity in ring-billed gulls Larus delawarensis and other hosts. Ecography 35: 530-538.

Locke S.A., Marcogliese D.J., Valtonen E.T. 2014: Vulnerability and diet breadth predict larval and adult parasite diversity in fish of the Bothnian Bay. Oecologia 174: 253-262.

Locke S.A., McLaughlin J.D., Marcogliese D.J. 2013: Predicting the similarity of parasite communities in freshwater fishes using the phylogeny, ecology and proximity of hosts. Oikos 122: $73-83$.

LuQue J.L., Poulin R. 2008: Linking ecology with parasite diversity in Neotropical fishes. J. Fish Biol. 72: 189-204.

Marsh R.E. 1994: Roof rats. In: S.E. Hyngstrom, R.M. Timm, G.E. Larson (Eds.) Prevention and Control of Wildlife Damage. University of Nebraska - Lincoln, pp. B-125-B-132.

Morand S., Bordes F., Chen H.W., Claude J., Cosson J.F., Galan M., Czirják G., Greenwood A.D., Latinne A., Michaux J., Ribas A. 2015: Global parasite and Rattus rodent invasions: the consequences for rodent-borne diseases. Integr Zool. 10: 409-423. 
Mouillot D., George-Nascimento M., Poulin R. 2005: Richness, structure and functioning in metazoan parasite communities. Oikos 109: 447-460.

Palmeirim M., Bordes F., Chaisiri K., Siribat P., Ribas A., Morand S. 2014: Helminth parasite species richness in rodents from Southeast Asia: role of host species and habitat. Parasitol. Res. 113: 3713-3726.

Poulin R. 2004: Macroecological patterns of species richness in parasite assemblages. Basic Appl. Ecol. 5: 423-434.

Poulin R. 2007: Are there general laws in parasite ecology? Parasitology 134: 763-776.

Poulin R. 2010: Decay of similarity with host phylogenetic distance in parasite faunas. Parasitology 137: 733-741.

Poulin R., Krasnov B.R., Mouillot D. 2011: Host specificity in phylogenetic and geographic space. Trends Parasitol. 27: 355-361.

R Development Core Team 2014: R: A language and environment for statistical computing. R Foundation for Statistical Computing, http://www.R-project.org/.

Rigaud T., Perrot-Minnot M.J., Brown M.J. 2010: Parasite and host assemblages: embracing the reality will improve our knowledge of parasite transmission and virulence. Proc. Biol. Sci. 277: 3693-3702.

Shochat E., Warren P.S., Faeth S.H., McIntyre N.E., Hope D. 2006: From patterns to emerging processes in mechanistic urban ecology. Trends Ecol Evol. 21: 186-191.

Spickett A., Junker K., Krasnov B.R., Haukisalmi V., MatTHEE S. 2017: Intra- and interspecific similarity in species composition of helminth communities in two closely-related rodents from South Africa. Parasitology 144: 12111-1220.

Timi J.T., LAnfranchi A.L. 2009: The importance of the compound community on the parasite infracommunity structure in a small benthic fish. Parasitol. Res. 104: 295-302.

Tімм R.M. 1994: Norway rats. In: S.E. Hyngstrom, R.M. Timm, G.E. Larson (Eds.) Prevention and Control of Wildlife Damage. University of Nebraska, Lincoln, pp. B-105 - B-120.

United Nations 2012: World Urbanization Prospects: The 2011 Revision, $302 \mathrm{pp}$

Werner P., ZAHNER R. 2010: Urban patterns and biological diversity: a review. In: N. Muller, P. Werner, J.G. Kelcey (Eds.) Urban Biodiversity and Design. Wiley, Oxford, pp. 145-173.

Cite this article as: Hancke D. and Suárez O.V. 2018: Structure of parasite communities in urban environments: the case of helminths in synanthropic rodents. Folia Parasitol. 65: 009 